\title{
Originals
}

\section{Hypertension in diabetic clinic patients and their siblings}

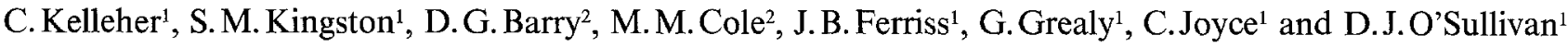 \\ Departments of ${ }^{1}$ Medicine and ${ }^{2}$ Statistics, Regional Hospital and University College, Cork, Ireland
}

Summary. The prevalence of hypertension was investigated in a systematically chosen sample of patients attending a diabetic clinic. One hundred ninety-one patients were classified as Type 1 (insulin-dependent), 183 were classified as Type 2 (non-insulin-dependent) and 12 were deemed unclassifiable. Two hundred fifty-five control subjects attending non-medical out-patient clinics were also examined under similar conditions. Hypertension was significantly $(p<0.001)$ more common among Type 2 patients (38\%) than among Type 1 patients $(15 \%)$ or control subjects $(16 \%)$. The difference between Type 2 patients and control subjects, but not between Type 2 and Type 1 patients, persisted when the influences of age and body mass index were controlled. We also investigated the prevalence of hypertension among the siblings of the hypertensive patients identified, together with a matched normotensive group. One hundred eighty-eight siblings were examined and historical details were obtained for a further 451 siblings. When age and body mass index were controlled for in examined siblings, the risk of hypertension was greater in those with a hypertensive proband than in those with a normotensive proband, in the control $(p<0.06)$ and Type 1 $(p<0.02)$ groups. Among the siblings of Type 2 probands, however, the risk of hypertension in those with a normotensive proband was at least as great as in those with a hypertensive proband, and greater than in those with a normotensive proband in the control $(p<0.10)$ or Type $1(p<0.05)$ groups. The prevalence of cardiovascular deaths was also similar in the siblings of normotensive and hypertensive Type 2 probands. We conclude that in our diabetic clinic there is an excess of hypertension among Type 2 patients. There may also be an excess of hypertension among the siblings of Type 2 patients.

Key words: Blood pressure, Type 1 (insulin-dependent) diabetes, Type 2 (non-insulin-dependent) diabetes, family history, hypertension.
Hypertension in the diabetic patient seems to accelerate both small vessel $[1,2]$ and large vessel $[3,4]$ disease. The balance of evidence also points to a greater than chance association between hypertension and diabetes. For example, Pell and D'Alonzo [5] found that hypertension was more common in diabetic patients than in an age, sex and weight-matched control population. Christlieb et al. [3] reported that in white diabetic patients aged more than 24 years, the prevalence of hypertension was higher than in either the Framingham population or the general United States population. Elevated systolic blood pressure in diabetic patients compared with non-diabetic control subjects has also been shown in children from adolescence onwards [6], in the Framingham study [7], and in elderly women [8].

In contrast, in a study of male civil servants aged 40 to 64 years, age-adjusted blood pressure levels were very similar in Type 1 (insulin-dependent) diabetic pat- ients, Type 2 (non-insulin-dependent) diabetic patients, and non-diabetic subjects [4]. In two diabetic clinic surveys, blood pressure levels did not differ significantly from retrospect control populations $[9,10]$, except in the very elderly [9]. A high prevalence of hypertension was reported in another uncontrolled clinic survey, however, especially among non-insulin-treated patients [11].

One possible explanation for the association of hypertension and diabetes is that similar genetic and/or environmental factors predispose to each condition. In a large Polish survey, a family history of hypertension was more common among the relatives of Type 2 patients than among the relatives of Type 1 patients, the former prevalence being significantly higher than that in the general population [12]. Tarn and Drury [13] recently reported higher diastolic blood pressure levels in young Type 1 diabetic males, than in their non-diabetic siblings. Those with the highest blood pressure 
levels had an increased prevalence of parental hypertension, suggesting that essential hypertension might contribute to the raised blood pressure levels observed [13].

We investigated whether or not there is an increased prevalence of hypertension among patients attending our diabetic clinic, compared with control patients, recognising that the findings do not necessarily reflect those in the general population. We also investigated whether or not there is an increased prevalence of hypertension among the siblings of hypertensive diabetic patients, comparing Type 1 and Type 2 patients in this regard.

\section{Subjects and methods}

\section{Selection of patients for study}

Our diabetic clinic is comprised of a racially homogeneous white population. Prior to each out-patient clinic every third patient on the attendance list was selected for study. Subjects who had been studied previously, or who were attending the clinic for the first or second time were excluded. Diabetes was diagnosed according to conventional criteria [14].

A control population was drawn from non-medical out-patient clinics in this hospital (such as fracture, orthopaedic, gynaecology and dermatology clinics), which were held at the same time of day as the diabetic clinic. Subjects attending for the first or second time were similarly excluded.

\section{Procedures}

On arrival at the clinic the patient's height and weight were measured. A research nurse completed a questionnaire with the patient, covering details on diabetes, hypertension, the presence of other diseases and treatment. Smoking and drinking habits were also noted. Any incomplete details were checked later with either the patient's family doctor or pharmacist, or both. On completion of the questionnaire, when the patient had been sitting quietly for $5 \mathrm{~min}$, a single blood pressure measurement was taken using a Hawksley randomzero sphygmomanometer. The diastolic pressure was recorded at the Korotkoff phase 5 sound. All blood pressure measurements, in both the diabetic and control groups, were carried out by the same observer. A large blood pressure cuff was used when patients were regarded as obese on physical appearance and after measuring weight and height. Blood was subsequently taken for measurement of blood glucose and $\mathrm{HbA}_{1}$ and a urine specimen was obtained for Labstix analysis.

\section{Study of siblings}

We also investigated blood pressure levels of the siblings of diabetic and control patients identified as hypertensive in the clinic survey, together with a group of normotensive patients, matched for age, sex, and when appropriate, for type of diabetes.

All probands were circulated with a questionnaire, asking for details on the number of siblings, whether alive or dead, and whether available siblings would agree to examination. Probands were also asked whether unavailable siblings were known to suffer from either hypertension or diabetes and, where siblings had died, for the cause of death. Deceased siblings were classified by cause of death into those who died of cardiac or cerebrovascular disease and those who died from other causes.

Siblings who agreed to examination were either seen at home or visited the Clinical Investigation Unit of this hospital. Three research nurses were trained in the survey procedure and obtained high interand intra-individual correlations of blood pressure recordings. Details of each subject's medical history and medications were obtained. Subjects rested supine for at least $5 \mathrm{~min}$ before three blood pressure measurements were obtained using a Hawksley randomzero sphygmomanometer; the average was then calculated. Diastolic phase 5 was used and a large cuff was again employed for obese arms. Resting pulse rate was also recorded, as were weight and height. Subjects then had a random blood glucose measurement and passed an untimed urine specimen for Labstix analysis and measurement of albumin concentration. When glycosuria was found, a standard glucose tolerance test was arranged. Urinary cultures were not available and $\log$ urinary albumin is reported because of skewed findings.

\section{Clinical definitions}

Hypertension was arbitrarily diagnosed when both systolic and diastolic blood pressure exceeded the 90th centile value for age and sex computed by Acheson [15], or when patients were already receiving anti-hypertensive drug treatment.

Patients were classified as Type 1 or Type 2 diabetic on clinical grounds, following review of the case-notes, using the guide-lines of Keen and Ng Tang Fui [14]. Diabetes in a sibling was diagnosed if the subject was already known to be diabetic, when blood glucose was $>11.1 \mathrm{mmol} / 1$ or when glucose tolerance was diabetic [14].

\section{Laboratory investigations}

Urine was examined for albumin and glucose using Labstix (Ames $\mathrm{Co}$, Slough, England). In sibling subjects, urinary albumin concentration was additionally measured by a standard radioimmunoassay method [16]. Plasma glucose was assayed using a conventional semiautomated glucose oxidase technique and $\mathrm{HbA}_{1}$ was measured by mini-column ion-exchange chromatography (Bio-Rad Laboratories Ltd, Richmond, Calif, USA; normal range 4.5-8.5\%).

\section{Statistical analysis}

Logistic regression was used to model the effect of background characteristics on the probability of hypertension. The logistic method assumes that the odds on being hypertensive are a product of factors, a group factor and factors for each of the background characteristics. The analysis was carried out using the BMDP package.

Chi-squared tests, Student's t-tests and one-way analysis of variance were used where appropriate. A $p$ value $<0.05$ was considered statistically significant.

\section{Results}

\section{Patients studied}

Three hundred eighty-six patients and 255 control subjects were examined. Details of these patients, including mean blood pressure, blood glucose and $\mathrm{HbA}_{1}$ measurements, are given in Table 1 . One hundred ninety-one diabetic patients were considered Type 1 and 183 were considered Type 2 . Of the latter, 27 were treated by diet alone, 128 by diet and oral hypoglycaemic agents and 28 were receiving insulin. A further 12 insulin-treated patients were considered unclassifiable and were excluded from subsequent detailed analysis.

Twelve percent of Type 1, 37\% of Type 2, and 14\% of control patients were receiving antihypertensive drugs. 


\section{Prevalence of hypertension}

Fifteen percent of patients with Type 1 diabetes, 38\% of patients with Type 2 diabetes and $16 \%$ of control patients had hypertension as defined (Table 1). Four of the 12 unclassifiable patients also had hypertension. Hypertension was significantly more common among Type 2 patients than among Type 1 patients or control subjects (each, $p<0.001$ ), while the prevalence was similar in Type 1 patients and control subjects. The prevalence of hypertension did not differ significantly between males and females in any group.

The prevalence of hypertension increased with increasing age and increasing body mass index $\left(\mathrm{kg} / \mathrm{m}^{2}\right)$, in each group. The increased prevalence of hypertension among Type 2 patients compared with control subjects persisted when controlled for age (one-sided test, $p<0.005$ ) and when controlled for age and body mass index, $(p<0.05)$. The difference between Type 1 and Type 2 patients was lost, however, when controlled for age or for age and body mass index.

Among Type 2 patients, there were no significant differences in the prevalence of hypertension in those treated by diet alone $(30 \%)$, in those treated by diet and oral hypoglycaemic drugs $(41 \%)$ and those treated with insulin $(32 \%)$.

Table 1. Details of Type 1 (insulin-dependent), Type 2 (non-insulindependent) and control patients examined. See text for definition of hypertension and for statistical analysis. BMI = Body mass index

\begin{tabular}{llll}
\hline & $\begin{array}{l}\text { Type 1 } \\
\text { patients }\end{array}$ & $\begin{array}{l}\text { Type 2 } \\
\text { patients }\end{array}$ & $\begin{array}{l}\text { Control } \\
\text { subjects }\end{array}$ \\
\hline Number & 191 & 183 & 255 \\
Percent male & $50 \%$ & $55 \%$ & $49 \%$ \\
Age (years) \pm SD & $41 \pm 19$ & $63 \pm 10$ & $49 \pm 19$ \\
BMI \pm SD & $24.7 \pm 3.2$ & $28.3 \pm 4.4$ & $25.0 \pm 4.3$ \\
Blood glucose & $12.3 \pm 6.2$ & $11.6 \pm 4.4$ & - \\
(mmol/1) \pm SD & & & \\
HbA $(\%) \pm S D$ & $11.1 \pm 2.6$ & $10.1 \pm 2.4$ & - \\
$\begin{array}{l}\text { Systolic BP (mm Hg) } \\
\pm \text { SD }\end{array}$ & & $131 \pm 23$ & $130 \pm 25$ \\
$\begin{array}{l}\text { Diastolic BP } \\
\text { (mm Hg) } \pm \text { SD }\end{array}$ & $78 \pm 11$ & $83 \pm 13$ & $80 \pm 15$ \\
Number (and & $29(15 \%)$ & $70(38 \%)$ & $42(16 \%)$ \\
percent) hypertensive & & & \\
\hline
\end{tabular}

\section{Albuminuria, smoking, alcohol, thiazide diuretics and indices of metabolic control}

Urine was Labstix positive for albumin in $24 \%$ of hypertensive and $11 \%$ of normotensive Type 1 patients $(p<0.08)$, and in $3 \%$ of both hypertensive and normotensive Type 2 patients.

The proportions of those who smoked were not significantly different among hypertensive and normotensive subjects (Type 1 patients $66 \%$ and $54 \%$ respectively; Type 2 patients $54 \%$ and $62 \%$ respectively; control patients $57 \%$ and $63 \%$ respectively). The proportions who drank alcohol were also similar among hypertensive and normotensive patients in the two diabetic groups (Type 1 patients $31 \%$ and $45 \%$ respectively; Type 2 patients $41 \%$ and $41 \%$ ) but in the control group fewer hypertensive than normotensive subjects drank alcohol ( $26 \%$ and $52 \%$ respectively, $p<0.001$ ). Six percent of control and $7.6 \%$ of Type 2 patients were taking thiazide diuretics. The diagnosis of diabetes preceded the introduction of thiazides in almost all the latter patients, however.

The relationships between blood pressure levels and concurrent measurements of blood glucose and $\mathrm{HbA}_{1}$ were examined in diabetic patients not receiving antihypertensive therapy. No associations were seen in either the Type 1 or Type 2 groups.

\section{Response to questionnaire}

Two hundred six diabetic probands and 104 non-diabetic control probands were circulated with the questionnaire (Table 2). There was an overall $78 \%$ response rate. The siblings of $25 \%$ of probands agreed to examination, while a further $28 \%$ of probands gave historical information, although their siblings were unavailable for examination, mainly because of distance. Twentytwo percent did not reply and the siblings of a further $12 \%$ refused examination.

Overall, 78 families agreed to examination, with a total of 343 siblings. Of these, 59 were already dead and 96 were too distant to participate. Historical data on those not examined was compiled and added to the available historical data on a further 86 families (with 296 siblings). Thus, historical data was available for a total of 451 siblings, alive or dead.

Table 2. Responses to the questionnaire, according to the diagnostic group of probands. The sample size of each subgroup is shown in parenthesis

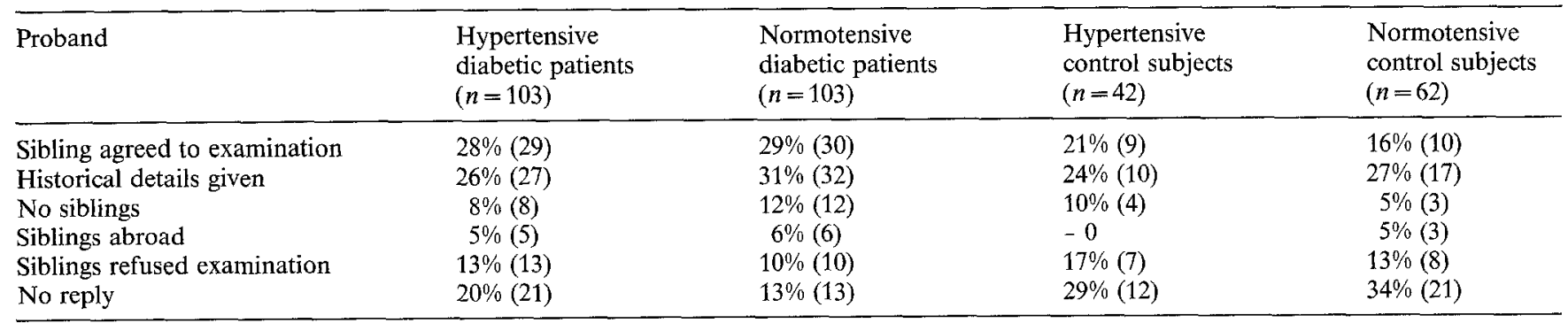


Table 3. Findings in the examined siblings of normotensive and hypertensive probands from the control, Type 1 and Type 2 groups of patients. See text for definitions of hypertension and diabetes and for statistical analysis. BMI = Body mass index

\begin{tabular}{|c|c|c|c|c|c|c|}
\hline & \multicolumn{2}{|c|}{$\begin{array}{l}\text { Siblings of } \\
\text { non-diabetic probands }\end{array}$} & \multicolumn{2}{|c|}{$\begin{array}{l}\text { Siblings of } \\
\text { Type } 1 \text { probands }\end{array}$} & \multicolumn{2}{|c|}{$\begin{array}{l}\text { Siblings of } \\
\text { Type } 2 \text { probands }\end{array}$} \\
\hline & $\begin{array}{l}\text { Normotensive } \\
\text { proband }\end{array}$ & $\begin{array}{l}\text { Hypertensive } \\
\text { proband }\end{array}$ & $\begin{array}{l}\text { Normotensive } \\
\text { proband }\end{array}$ & $\begin{array}{l}\text { Hypertensive } \\
\text { proband }\end{array}$ & $\begin{array}{l}\text { Normotensive } \\
\text { proband }\end{array}$ & $\begin{array}{l}\text { Hypertensive } \\
\text { proband }\end{array}$ \\
\hline $\begin{array}{l}\text { Number of siblings } \\
\text { examined }\end{array}$ & 24 & 16 & 43 & 26 & 33 & 46 \\
\hline Age (years) $\pm \mathrm{SD}$ & $62 \pm 14$ & $56 \pm 9$ & $52 \pm 14$ & $44 \pm 17$ & $62 \pm 12$ & $65 \pm 8$ \\
\hline $\mathrm{BMI} \pm \mathrm{SD}$ & $24.0 \pm 3.6$ & $25.3 \pm 4.1$ & $24.7 \pm 3.5$ & $24.2 \pm 5.2$ & $26.7 \pm 6.0$ & $25.3 \pm 4.3$ \\
\hline Alcohol drinkers & $54 \%$ & $56 \%$ & $74 \%$ & $74 \%$ & $54 \%$ & $52 \%$ \\
\hline Smokers & $33 \%$ & $56 \%$ & $46 \%$ & $40 \%$ & $41 \%$ & $44 \%$ \\
\hline Number with diabetes & 1 & 0 & 1 & 2 & 4 & 6 \\
\hline $\begin{array}{l}\text { Random blood glucose } \\
(\mathrm{mmol} / \mathrm{l})\end{array}$ & $5.2 \pm 1$ & $5.2 \pm 1.5$ & $5.1 \pm 2$ & $5.5 \pm 3$ & $5.9 \pm 3$ & $5.8 \pm 2$ \\
\hline $\begin{array}{l}\text { Log urinary albumin } \\
(\mu \mathrm{g} / \mathrm{ml}) \pm \mathrm{SD}\end{array}$ & $0.73 \pm 0.46$ & $1.08 \pm 0.59$ & $0.80 \pm 0.45$ & $0.85 \pm 0.35$ & $1.09 \pm 0.66$ & $0.92 \pm 0.39$ \\
\hline Systolic BP $(\mathrm{mm} \mathrm{Hg}) \pm \mathrm{SD}$ & $131 \pm 23$ & $146 \pm 28$ & $133 \pm 19$ & $143 \pm 22$ & $149 \pm 24$ & $146 \pm 24$ \\
\hline Diastolic $\mathrm{BP}(\mathrm{mm} \mathrm{Hg}) \pm \mathrm{SD}$ & $81 \pm 14$ & $89 \pm 17$ & $76 \pm 14$ & $82 \pm 16$ & $87 \pm 14$ & $84 \pm 14$ \\
\hline Percent hypertensive & $20.8 \%$ & $37.5 \%$ & $7.0 \%$ & 19.2 & $48.5 \%$ & $43.5 \%$ \\
\hline Odds Factor $\pm \mathrm{SE}$ & 1.0 & $3.43 \pm 2.69$ & $0.42 \pm 0.35$ & $2.36 \pm 1.92$ & $2.96 \pm 1.98$ & $2.33 \pm 1.44$ \\
\hline
\end{tabular}

Table 4. The prevalence of hypertension in examined cases and based on historical data, and the prevalence of cardiac and cerebrovascular deaths, among the siblings of control, Type 1 and Type 2 probands. The sample size of each sub-group is shown in parenthesis. See text for statistical analysis

\begin{tabular}{|c|c|c|c|c|c|c|}
\hline & \multicolumn{2}{|c|}{ Examined cases } & \multicolumn{2}{|l|}{ Historical cases } & \multicolumn{2}{|c|}{ Decreased cases } \\
\hline & $\begin{array}{l}\text { Normotensive } \\
\text { proband }\end{array}$ & $\begin{array}{l}\text { Hypertensive } \\
\text { proband }\end{array}$ & $\begin{array}{l}\text { Normotensive } \\
\text { proband }\end{array}$ & $\begin{array}{l}\text { Hypertensive } \\
\text { proband }\end{array}$ & $\begin{array}{l}\text { Normotensive } \\
\text { proband }\end{array}$ & $\begin{array}{l}\text { Hypertensive } \\
\text { proband }\end{array}$ \\
\hline Non-diabetic control subjects & $20.8 \%(24)$ & $37.5 \%(16)$ & $1.6 \%(63)$ & $13.6 \%(22)$ & $20.7 \%(29)$ & $46.7 \%(15)$ \\
\hline Type 1 diabetic patients & $7.0 \%(43)$ & $19.2 \%(26)$ & $6.4 \%(47)$ & $0 \%(13)$ & $19.4 \%(31)$ & $40.0 \%(10)$ \\
\hline Type 2 diabetic patients & $48.5 \%(33)$ & $43.5 \%(46)$ & $4.7 \%(64)$ & $19.7 \%(61)$ & $29.6 \%(27)$ & $31.9 \%(69)$ \\
\hline
\end{tabular}

\section{Examined siblings}

The findings in the examined siblings are summarised in Table 3, including mean blood pressure and blood glucose measurements in all groups. Eighty-five percent of those classified as hypertensive were already receiving antihypertensive treatment. The prevalence of hypertension was greater among the siblings of hypertensive probands than among the siblings of normotensive probands in the control $(p<0.1)$ and Type $1(p<$ 0.05 ) groups, but not among Type 2 siblings.

Body mass index was not significantly different in the various sub-groups, but the siblings of Type 1 probands were younger than siblings in the other groups $(p<0.001)$. Increasing age and body mass index were related to the presence of hypertension in each group, and these effects did not vary significantly from group to group. On the other hand, gender, concurrent blood glucose concentration, log urinary albumin, a history of smoking or alcohol ingestion did not show an independent influence.

Taking the normotensive non-diabetic group as standard, the odds factors for the presence of hypertension, adjusted for age and body mass index, are shown in Table 3. Among the siblings of non-diabetic probands, the odds of being hypertensive were more than three-fold greater in those with hypertensive probands than in those with normotensive probands (onesided test, $p<0.06$ ), while for the siblings of Type 1 probands the odds were more than five-fold greater $(p<0.02)$. Among the siblings of Type 2 probands, however, the odds for having hypertension were at least as great in the siblings of normotensive as in the siblings of hypertensive probands.

Among the siblings of normotensive probands, the odds of being hypertensive in the Type 2 group were almost three-fold greater than in the control group $(p<0.10)$ and more than seven-fold greater than in the Type 1 group $(p<0.05)$.

\section{Historical information}

The prevalence of hypertension in examined cases, of reported hypertension in the historical data and of reported deaths from cardiac and cerebrovascular causes are compared in Table 4. Using an overall chi-squared test it was found that results based on examined cases and reported deaths agreed $(p>0.20)$, whereas both assessments differed significantly from findings based on histories ( $p<0.001$ in each case). 


\section{Discussion}

Surveys of diabetic clinic populations are prone to bias, as the proportion of Type 1 and Type 2 patients in this study suggests. This survey does, however, show an increased prevalence of hypertension among Type 2 patients compared with control subjects, not fully explained by age and body mass index, in contrast to some other clinic reports $[9,10]$.

An increased prevalence of hypertension among the relatives of hypertensive patients, compared with the relatives of normotensive subjects, is well described in non-diabetic populations [17]. Balme and Cole reported that a family history of hypertension was also more common in hypertensive than in normotensive diabetic patients, although they did not distinguish between Type 1 and Type 2 patients [18]. Similarly, among examined siblings in this study, hypertension was more common in those with hypertensive probands than in those with normotensive probands, in both the control and Type 1 groups. A different pattern emerged in the Type 2 group, however, with hypertension occurring at least as often in the siblings of normotensive probands as in the siblings of hypertensive probands. Furthermore, hypertension was more frequent among the siblings of normotensive probands in the Type 2 group than among the siblings of normotensive probands in the other groups, even when the influences of age and body mass index were controlled. The data of Krolewski et al. suggest an increased prevalence of essential hypertension among the relatives of Type 2 patients, based on a common genetic and/or environmental background [12]. The present data are in keeping with this suggestion. The mechanism for an association between Type 2 diabetes and essential hypertension is not clear. It might, for example, be related to the insulin resistance which can occur in each condition [19].

The low prevalence of hypertension based on historical information in all groups may be explained by a poor knowledge of the health of siblings living far away or abroad. As a diagnosis of hypertension in the examined group was mainly based on established treatment, it is unlikely that the prevalence was markedly over-estimated in that group. The findings thus illustrate a striking under-estimation of hypertension based on family history in all groups. More firm family information is likely to be available for siblings who have died, and the similar prevalence of cardiovascular deaths in the siblings of normotensive and hypertensive Type 2 patients, in contrast to the other groups, seems to support the findings based on examined cases.

We cannot exclude bias in the siblings survey either. It is possible, for example, that the siblings of hypertensive patients would co-operate more readily than those of normotensive probands [17]. This, however, would not explain the high prevalence of hypertension among the siblings of normotensive as well as hypertensive probands in the Type 2 examined group, and the contrast with the other groups.

We arbitrarily diagnosed hypertension when both systolic and diastolic pressures were above the 90th centile for age and sex; this was to minimise a spuriously high blood pressure associated with measurement on a single occasion, which particularly affects systolic pressure [20]. In practice, the vast majority of hypertensive patients were already taking antihypertensive therapy, in both the clinic and siblings surveys. Blood pressure was not particularly well controlled, however, and uncorrected mean levels showed patterns in keeping with the corrected findings. There are also potential errors in clinically classifying patients as having Type 1 or Type 2 diabetes; our patients were classified according to current clinical criteria [14].

In conclusion, we found an increased prevalence of hypertension among Type 2 clinic patients compared with control subjects. The prevalence of hypertension among the siblings of Type 2 patients was also high, suggesting a link with essential hypertension.

Acknowledgement. We are grateful for the support of the Medical Research Council of Ireland.

\section{References}

1. Mogensen CE (1982) Long-term antihypertensive treatment inhibiting progression of diabetic nephropathy. $\mathrm{Br}$ Med J 285: $685-688$

2. Parving HH, Andersen AR, Smidt UM, Svendsen PA (1983) Early aggressive antihypertensive treatment reduces rate of decline in kidney function in diabetic nephropathy. Lancet I: 1175-1179

3. Christlieb AR, Warram JH, Krolewski AS, Busick EJ, Ganda OP, Asmal AC, Soeldner JS, Bradley RF (1981) Hypertension: the major risk factor in juvenile-onset insulin-dependent diabetics. Diabetes 30 [Suppl 2]: 90-96

4. Jarrett RJ (1984) The epidemiology of coronary heart disease and related factors in the context of diabetes mellitus and impaired glucose tolerance. In: Jarrett RJ (ed) Diabetes and Heart Disease. Elsevier, Amsterdam, pp 1-23

5. Pell S, D'Alonzo CA (1967) Some aspects of hypertension in diabetes mellitus. JAMA 202: 104-110

6. Moss AJ (1962) Blood pressure in children with diabetes mellitus. Pediatrics 130: 932-936

7. Garcia MJ, McNamara PM, Gordon T, Kannell WB (1974) Morbidity and mortality in diabetics in the Framingham population: sixteen year follow-up study. Diabetes 23: 105-111

8. Barrett-Connor E, Criqui MH, Klauber MR, Holdbrook M (1981) Diabetes and hypertension in a community of older adults. Am J Epidemiol 113: 276-284

9. Freedman P, Moulton R, Spencer AG (1958) Hypertension and Diabetes Mellitus. Q J Med 27: 293-305

10. Keen H, Track NS, Sowry GSC (1975) Arterial pressure in clinically apparent diabetics. Diabete Metab 1: 159-178

11. Pacy PJ, Dodson PM, Beevers M, Fletcher RF, Taylor KG (1985) Prevalence of hypertension in white, black and Asian diabetics. Diabetic Medicine 2: 125-130

12. Krolewski AS, Czyzyk A, Kopczynski J, Rywik S (1981) Prevalence of diabetes mellitus, coronary heart disease and hypertension in the families of insulin dependent and insulin independent diabetics. Diabetologia 21: 520-524 
13. Tarn AC, Drury PL (1986) Blood pressure in children, adolescents and young adults with Type 1 (insulin-dependent) diabetes. Diabetologia 29: 275-281

14. Keen H, Ng Tang Fui S (1982) The definition and classification of Diabetes Mellitus. Clin Endocrinol Metab 11: 279-305

15. Acheson RM (1973) Blood pressure in a national sample of U.S. adults: percentile distribution by age, sex and race. Int J Epidemiol 2: 293-301

16. Keen H, Chlouverakis C (1963) An immunoassay method for urinary albumin at low concentration. Lancet II: 913-916

17. Heller RF, Robinson N, Peart WS (1980) Value of blood pressure measurement in relatives of hypertensive patients. Lancet $\mathrm{I}$ : 1206-1208

18. Balme HW, Cole L (1951) The heredity of hypertension in diabetes mellitus. Q J Med 20: 335-351
19. Lever AF (1986) Slow pressor mechanisms in hypertension: a role for hypertrophy of resistance vessels? J Hypertens 4: $515-524$

20. Dunne JF (1969) Variation of blood pressure in untreated hypertensive out-patients. Lancet I: 391-392

Received: 14 August 1987

and in revised form: 24 December 1987

Prof. J. B. Ferriss

Department of Medicine

Regional Hospital

Cork

Ireland 